\title{
Combination therapy with lercanidipine and enalapril in the management of the hypertensive patient: an update of the evidence
}

This article was published in the following Dove Press journal:

Vascular Health and Risk Management

I5 November 2016

Number of times this article has been viewed

\section{Christina Antza' \\ Stella Stabouli² \\ Vasilios Kotsis'}

'Hypertension Center, Third Department of Medicine, Papageorgiou Hospital, ${ }^{2}$ First Department of Pediatrics, Hippokration Hospital, Aristotle University of Thessaloniki, Thessaloniki, Greece
Correspondence: Vasilios Kotsis Third Department of Internal Medicine, Hypertension-24h Ambulatory Blood Pressure Monitoring Center, Papageorgiou Hospital, Aristotle University of Thessaloniki, Thessaloniki, Greece

Tel +306974748860

Email vkotsis@auth.gr
Abstract: Hypertension is an important risk factor for premature death as it increases the probability of stroke, myocardial infarction, and heart failure. Antihypertensive drugs can decrease cardiovascular $(\mathrm{CV})$ morbidity and mortality. The majority of hypertensive patients need more than one antihypertensive agent to attain blood pressure (BP) targets. Monotherapy can effectively reduce BP only in $20 \%-40 \%$ of patients. Multiple mechanisms including increased peripheral vascular resistance, increased cardiac work, and hypervolemia are involved in the pathogenesis of hypertension. Targeting multiple pathways may more potently reduce BP. Increasing the dose of a single agent in many cases does not provide the expected BP-lowering effect because the underlying mechanism of the BP increase is either different or already corrected with the lower dose. Moreover, drugs acting on different pathways may have synergistic effects and thus better control hypertension. It is well known that diuretics enhance the actions of renin-angiotensin aldosterone system and activate it as a feedback to the reduced circulated blood volume. The addition of a renin-angiotensin aldosterone system blocker to a diuretic may more effectively reduce $\mathrm{BP}$ because the system is upregulated. Reducing the maximal dose of an agent may also reduce possible side effects if they are dose dependent. The increased prevalence of peripheral edema with higher doses of calcium channel blockers (CCBs) is reduced when renin-angiotensin aldosterone system blockers are added to CCBs through vein dilation. The effectiveness of the combination of enalapril with lercanidipine in reducing BP, the safety profile, and the use of the combination of angiotensin-converting enzyme inhibitors with CCBs in clinical trials with excellent $\mathrm{CV}$ hard end point outcomes make this combination a promising therapy in the treatment of hypertension.

Keywords: angiotensin-converting enzyme inhibitors, calcium channel blockers, hypertension, lercanidipine, enalapril

\section{Introduction}

Blood pressure (BP) control mechanisms such as cardiac output, peripheral vascular resistance, and circulating blood volume result in a variety of hypertensive phenotypes. Each mechanism may contribute in a different extent to increase BP in a hypertensive patient, and the choice of the most suitable treatment for each patient is usually an important task. ${ }^{1}$ Cardiac output control is important to maintain an adequate tissue blood flow. Increased cardiac output in hypertension is driven either by a higher stroke volume or by a higher heart rate. Decreased total peripheral resistance increases cardiac output and decreases arterial pressure. ${ }^{2}$ When tissue blood flow falls below normal, the kidneys retain water and salt, and this retention occurs until flow and BP rise back to normal. These physiological mechanisms are 
also under the control of the central and the autonomous nervous systems. Elevated peripheral vascular resistance appears to be the primary hemodynamic abnormality associated with high BP. Peripheral vascular resistance affects organ blood flow through multiple physiological mechanisms including the role of sympathetic nervous system in the vessels, the effect of circulating or local vasoactive hormones, such as angiotensin II (AT-II), epinephrine and norepinephrine, antidiuretic hormone, atrial natriuretic peptide, and endothelin, and the actions of endothelial factors, such as nitric oxide. ${ }^{3,4}$ This complexity of hypertension mechanisms results in a varied individual response to antihypertensive treatment and the need for treatment individualization. ${ }^{5}$

Accounting for the different BP mechanisms, scientists were led to the discovery and development of targeted antihypertensive therapy. Hydralazine was the first vasodilator and was followed by calcium channel blockers (CCBs) on vascular smooth muscle cells, blockade of post-synaptic alpha-adrenoceptors on peripheral sympathetic neurons (alpha blockers), and finally, vasodilatation achieved by blockade of the renin-angiotensin-aldosterone system (RAAS) (angiotensin-converting enzyme [ACE] inhibitors, angiotensin receptor blockers [ARBs], direct renin inhibitors [DRIs]). When these molecules are administered to a heterogeneous population, BP responses were wide ranging. ACE inhibitor treatment may cause acute renal deterioration in severe stenosis of both renal arteries or in renal artery stenosis of a single functioning kidney. ACE-induced acute renal failure is usually associated with hypotension symptoms, which is reversible upon treatment discontinuation. ${ }^{6}$ In patients with low renin hypertension, such as hypertension in the elderly and in individuals of African origin, where the activity of the RAAS is generally suppressed, BP reductions with an ACE inhibitor may be small. ${ }^{7}$ A meta-analysis of 354 randomized double-blind placebo-controlled trials of monotherapy reports that average $\mathrm{BP}$ responses to single agents were $9.1 \mathrm{mmHg}$ for systolic and 5.5 mmHg for diastolic BP at a standard dose. ${ }^{8,9}$ Therefore, a satisfactory BP response is rarely reached with monotherapy alone, except for patients near the normal thresholds. What is the next step if BP has not reached the goal after the patient has been treated with monotherapy? Should we double the dose of the monotherapy or start combination drugs in low doses?

Combination therapy improves rates of BP control and requires less time to achieve target $\mathrm{BP}^{10-12}$ with equivalent ${ }^{13}$ or better tolerability ${ }^{14}$ than higher dose monotherapy.
A meta-analysis of $>40$ studies has shown that combining two agents from any two classes of antihypertensive drugs increases BP reduction much more than increasing the dose of one agent. ${ }^{15}$ Additional benefits may include cost savings and better compliance. ${ }^{12,14,16}$ Possible drug combinations are shown in Figure 1 and include beta blockers-diuretics, ${ }^{17}$ ARBs-diuretics, ${ }^{18,19}$ ACE inhibitors-diuretics, ${ }^{17} \mathrm{CCBs}-$ ACE inhibitors, ${ }^{20,21} \mathrm{CCBs}$-diuretics, ${ }^{18}$ and a thiazide plus a potassium-sparing diuretic. ${ }^{17}$

Randomized clinical trials compared different combinations of two antihypertensive drugs or combination of two drugs with placebo for their effectiveness in BP reduction and in cardiovascular $(\mathrm{CV})$ hard end points such as $\mathrm{CV}$ deaths and hospitalization of patients for myocardial infarction, stroke, and heart failure. In the LIFE trial, ${ }^{22}$ hypertensive patients were randomized to initial treatment with either losartan or atenolol. Hydrochlorothiazide was added in order to achieve BP goals. After a 5-year follow-up, the composite primary $\mathrm{CV}$ end point was reduced by $13 \%$ in the losartanbased group compared with the atenolol-based group. The major benefit was seen in the secondary stroke end point, which was reduced by $25 \%$ in the losartan-based group. In the VALUE study, ${ }^{23}$ hypertensive patients were randomized to either valsartan or amlodipine. Hydrochlorothiazide was added to each group in attempting to achieve the goal of BP. Other add-on drugs were similar in the two treatment groups. The mean follow-up was 4.2 years. BP was reduced in the amlodipine-based treatment group more effectively and earlier than that in the valsartan group. Myocardial infarction and strokes were less in the amlodipine-based treatment group compared with the valsartan-based group.

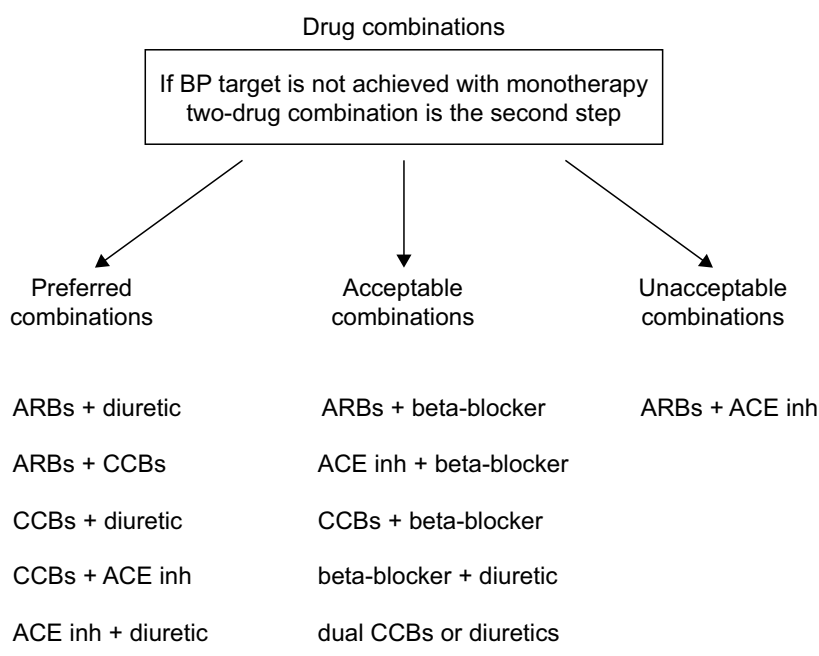

Figure I Drug combinations.

Abbreviations: ACE inh: angiotensin-converting enzyme inhibitors; ARBs, angiotensin receptor blockers; BP, blood pressure; CCBs, calcium channel blockers. 
In the HYVET study, ${ }^{24}$ hypertensives, aged $>80$ years, received either the diuretic indapamide or a matching placebo. The ACE inhibitor perindopril, or matching placebo, was added if necessary to achieve the BP target. The combination of indapamide with perindopril was superior in reducing stroke (30\%) and heart failure (64\%) incidence, compared with placebo. In the HOPE trial, the administration of ramipril in patients with a history of myocardial infarction resulted in reduction of $\mathrm{BP}$ and incidence of $\mathrm{CV}$ events compared with the placebo group. ${ }^{25}$ In the FEVER trial, ${ }^{26}$ the calcium antagonist felodipine was compared to placebo in treated patients with $\mathrm{BP}<160 / 90 \mathrm{mmHg}$ on previous antihypertensive treatment. In the felodipine group, the incidence of all CV end points was statistically significantly reduced.

In the ACCOMPLISH trial, ${ }^{27}$ hypertensive patients were randomized to a combination of benazepril with either hydrochlorothiazide or amlodipine. Patients were followed for 3 years. CV events were significantly reduced by $20 \%$ in the benazepril/amlodipine group compared with the benazepril/hydrochlorothiazide group. Myocardial infarction incidence was reduced by $22 \%$ and stroke incidence by $16 \%$ in benazepril/amlodipine group compared with benazepril/hydrochlorothiazide group. The superior benefits of the benazepril/amlodipine combination were seen in both diabetic and nondiabetic patients. In the ASCOT trial, ${ }^{28}$ hypertensive patients with no prior history of coronary heart disease were randomized to either amlodipine or atenolol. Perindopril or the diuretic bendroflumethiazide was added to each group, respectively, in an attempt to achieve BP targets. After a 5.5-year follow-up, the trial was stopped prematurely on the advice of the Data Safety Monitoring Committee because of highly significant outcome benefits in favor of the amlodipine/perindopril group. All CV events were reduced by $26 \%$, stroke by $23 \%$, and all-cause mortality by $11 \%$ with the amlodipine-based combination compared with the atenolol-based combination. The INVEST study ${ }^{29}$ compared mortality and morbidity outcomes in patients with hypertension and coronary artery disease treated with either a calcium antagonist strategy or a non-calcium antagonist drug. The verapamil group, in which it was added trandolapril if necessary, was compared with atenolol to which hydrochlorothiazide was added if necessary to achieve BP goals. After a 2.7-year follow-up in 22,576 hypertensives with established coronary artery disease, the study showed that combined CV outcome was similar in the two groups. According to the EUROPA trial, ${ }^{30}$ patients with coronary disease were protected by $\mathrm{CV}$ disease when BP was lowered by perindopril with the possible addition of indapamide.

In conclusion, combination therapies are more effective in the reduction of $\mathrm{BP}$ than single agents. ACE inhibitors and CCBs have promising results from clinical trials compared to beta blockers with diuretics (Table 1).

Table I Combination of antihypertensive therapies

\begin{tabular}{|c|c|c|}
\hline Study & Combination & Result \\
\hline LIFE $^{22}$ & Losartan $+\mathrm{HCT}$ vs atenolol $+\mathrm{HCT}$ & 5 years primary $\mathrm{CV}$ end point: $13 \%$ reduction \\
\hline VALUE $^{23}$ & Amlodipine $+\mathrm{HCT} /$ valsartan $+\mathrm{HCT}$ vs valsartan or amlodipine alone & 2 years BP control: $14.4 \%$ reduction \\
\hline \multirow[t]{3}{*}{ HYVET $^{24}$} & Indapamide alone or indapamide + perindopril vs placebo & 2 years CV event: $34 \%$ reduction \\
\hline & & 2 years heart failure: $64 \%$ reduction \\
\hline & & 2 years stroke: $30 \%$ reduction \\
\hline \multirow[t]{3}{*}{$\mathrm{HOPE}^{25}$} & Ramipril vs placebo & 5 years CV events: $2 \%$ reduction \\
\hline & & 5 years myocardial infarction: $2.4 \%$ reduction \\
\hline & & 5 years stroke: $1.5 \%$ reduction \\
\hline \multirow[t]{3}{*}{ FEVER $^{26}$} & Felodipine $+\mathrm{HCT}$ vs placebo $+\mathrm{HCT}$ & 3.3 years $C V$ events: $27 \%$ reduction \\
\hline & & 3.3 years cardiac events: $35 \%$ reduction \\
\hline & & 3.3 years death by any cause: $31 \%$ reduction \\
\hline \multirow[t]{3}{*}{ ACCOMPLISH $^{27}$} & Benazepril + amlodipine vs benazepril $+\mathrm{HCT}$ & 3 years CV event: $20 \%$ reduction \\
\hline & & 3 years myocardial infarction: $22 \%$ reduction \\
\hline & & 3 years stroke: $16 \%$ reduction \\
\hline \multirow[t]{3}{*}{ ASCOT 28} & Amlodipine + perindopril vs atenolol + bendroflumethiazide & 5.5 years CV event: $26 \%$ reduction \\
\hline & & 5.5 years stroke: $23 \%$ reduction \\
\hline & & 5.5 years all-cause mortality: II \% reduction \\
\hline INVEST $^{29}$ & Verapamil + trandolapril vs atenolol $+\mathrm{HCT}$ & 2.7 years CV disease: similar outcome \\
\hline \multirow[t]{3}{*}{ EUROPA $^{30}$} & Patients medication + perindopril vs patients medication + placebo & 4.2 years $\mathrm{CV}$ mortality: $14 \%$ reduction \\
\hline & & 4.2 years nonfatal myocardial infarction: $22 \%$ reduction \\
\hline & & 4.2 years total mortality: II\% reduction \\
\hline
\end{tabular}

Abbreviations: $\mathrm{BP}$, blood pressure; $\mathrm{CV}$, cardiovascular; $\mathrm{HCT}$, hydrochlorothiazide. 


\section{Review of pharmacology, mode of action, and pharmacokinetics of combination of lercanidipine with enalapril}

Lercanidipine is a third-generation dihydropyridine CCB in which a chiral carbon atom at position 4 of the 1,4-dihydropyridine ring is present. Lercanidipine hydrochloride is a microcrystalline, citrine powder, practically insoluble in water. ${ }^{31,32}$ Its antihypertensive effect is due to inhibiting calcium entry through L-type calcium channels in smooth muscle cells of the CV system, leading to peripheral vasodilatation. ${ }^{33-35}$ It is a highly lipophilic drug and has a slower onset and longer duration of action than other dihydropyridines, ${ }^{36}$ whereas the high proportion of L-type calcium channels in arteries provides high vasoselectiveness. ${ }^{35}$ Lercanidipine is a well-tolerated drug with few adverse events; it does not cause sympathetic activation or reflex tachycardia and provides a renoprotective effect. ${ }^{37,38}$ Regarding its pharmacokinetics, lercanidipine is classified as a once-a-day drug and demonstrates a short plasma half-life of 3 hours, with a long duration of action. It is rapidly absorbed from the gastrointestinal tract and has an absolute bioavailability of $10 \%$ in fed patient, indicating that it should be administrated before meals. Lercanidipine is metabolized by cytochrome P450 3A4 and is excreted to a similar extent in the urine and feces. Lercanidipine given at doses up to $20 \mathrm{mg}$ provides effective antihypertensive action, and these doses are well tolerated. However, the drug is not recommended in patients with advanced renal (glomerular filtration rate $<10 \mathrm{~mL} / \mathrm{min}$ or dialysis) or hepatic insufficiency. ${ }^{39-41}$ Enalapril maleate is the maleate salt of enalapril, chemically described as $(S)$-1[ $N$-[1-(ethoxycarbonyl)-3-phenylpropyl]-L-alanyl]-L-proline, (Z)-2-butenedioate salt (1:1). Enalapril maleate is a white to off-white crystalline powder. It is soluble in water, ethanol, and methanol. ${ }^{42,43}$ Enalapril is an orally administered prodrug that is hydrolyzed to the active metabolite, enalaprilat, that is able to reduce plasma levels of AT-II by blocking the last step of its activation and providing antihypertensive actions. ${ }^{44}$ After oral administration, the peak serum concentrations of enalapril occur within $\sim 1$ hour. The respective concentrations of enalaprilat are achieved after 4-6 hours. Enalapril has a half-life of only 1.3 hours, but enalaprilat has a plasma half-life of $\sim 11$ hours. Increasing the dose in the elderly may increase the risk of adverse effects. In patients with advanced renal failure (mean GFR $=15 \mathrm{~mL} / \mathrm{min}$ ), a low dose of enalapril $(1.25-5 \mathrm{mg})$ afforded the same degree of BP control and renoprotection as a high dose $(2.5-30 \mathrm{mg})$ with less side effects (Table 2). ${ }^{45}$
Table 2 Pharmacology of lercanidipine and enalapril

\begin{tabular}{lll}
\hline $\begin{array}{l}\text { Pharmacological } \\
\text { characteristics }\end{array}$ & Lercanidipine & Enalapril \\
\hline Molecular weight & 648.2 & 492.53 \\
Form & Citrine powder & Off-white powder \\
Solubility in water & No & Yes \\
Half-life & 3 hours & 1.3 hours \\
Absorption & Gastrointestinal & Gastrointestinal \\
Secretion & Urine, feces & Urine, feces \\
\hline
\end{tabular}

Dihydropyridine CCBs may induce reflex activation of the sympathetic nervous system and the RAAS. Moreover, edema is the side effect of the vasodilatory actions of the CCBs and may be related to arteriolar dilatation that causes increased intracapillary pressure. High doses of lercanidipine when compared to the high dose of amlodine or nifedipine had significantly fewer side effects associated with peripheral vasodilatation such as leg edema, swelling, flushes, headache, and palpitations. ${ }^{40}$ The addition of an ACE inhibitor or an ARB to a dihydropyridine CCB significantly reduces vasodilatory edema mainly from veining dilatation that reduces capillary pressure. ${ }^{46}$ Since CCBs may promote a negative sodium balance and an increase in AT-II levels, this action may reinforce the antihypertensive effect of ACE inhibition when $\mathrm{ACE}$ inhibitor is added to $\mathrm{CCBs} .{ }^{46,47}$

\section{Efficacy of the fixed combination of lercanidipine and enalapril}

Several trials have demonstrated the benefits of the fixed combination of lercanidipine and enalapril. The efficacy of lercanidipine and enalapril has been assessed in patients with hypertension, as well as in elderly and in diabetics. Puig et $\mathrm{l}^{48}$ described the additive effects of lercanidipine and enalapril. Seventy-five patients aged 60-85 years were randomized. Each patient received one of the following four treatments in a randomized order for 4 weeks each: lercanidipine $10 \mathrm{mg}$, enalapril $20 \mathrm{mg}$, lercanidipine $10 \mathrm{mg}$ plus enalapril $20 \mathrm{mg}$ (lercanidipine/enalapril), and placebo. The combination therapy with lercanidipine/enalapril was well tolerated and had additive antihypertensive effects on both ambulatory and office BP in elderly patients. Patients with diabetes and mild-to-moderate hypertension were included in a multicenter, double-blind, randomized trial. ${ }^{49}$ After a 2 -week placebo run-in followed by 4 weeks on enalapril $20 \mathrm{mg}$, nonresponders were randomized to add-on therapy with either lercanidipine $10 \mathrm{mg}$ or hydrochlorothiazide $12.5 \mathrm{mg}$. At the end of the study, lercanidipine decreased diastolic BP by a mean of $9.3 \mathrm{mmHg}$ and hydrochlorothiazide by a mean of $7.4 \mathrm{mmHg}$, while the respective reductions in systolic BP were $9.6 \mathrm{mmHg}$ and $6 \mathrm{mmHg}$. In an observational 
study enrolling 315 patients, followed up for a mean of $2.88 \pm 1.75$ months after starting lercanidipine/enalapril, the corresponding reductions in systolic BP and diastolic BP were $11.4 \%$ and $11.3 \%$, respectively. Systolic BP was reduced independently of sex and age, and diastolic BP was reduced independently of sex. The BP control rates significantly increased from $10.2 \%$ at baseline to $51 \%$ after a mean of 2.88 months of treatment with lercanidipine/enalapril. Last but not least, adverse effects were seen in only one patient, who developed a persistent dry cough. ${ }^{50}$

\section{Metabolic actions of the fixed combination}

Lipoprotein(a) (Lp(a)) is composed of a particle of lowdensity lipoprotein attached to a large, hydrophilic glycoprotein, apolipoprotein A, and potentiates thrombosis, because it inhibits the binding of plasminogen-binding proteins on the surface of endothelial cells. Lp(a) can act as a marker of vascular or tissue injury. Soluble receptor of advanced glycation end products (sRAGE) is a member of the immunoglobulin cell-surface molecules that are the receptors for advanced glycation end products (AGEs) that have proinflammatory action and have been related to endothelial dysfunction, arterial stiffening, and hypertension. sRAGE has AGE-binding properties and acts as an inhibitor of AGEmediated effects. Higher plasma levels of sRAGE have been reported to be associated with lower incidence of coronary atherosclerosis and to be lower to patients with carotid and femoral atherosclerosis. Soluble CD40 ligand is involved in the pathogenesis of vascular damage and has been regarded as a molecular marker connecting inflammation, thrombosis, and angiogenesis. Finally, serum myeloperoxidase (MPO) reduces nitric oxide (NO) bioavailability causing impaired endothelium-dependent dilation by direct consumption of NO and production of reactive oxygen species that decrease tetrahydrobiopterin bioactivity and NO production. The role of the combination of lercanidipine/enalapril in biomarkers of endothelial damage including LP(a), sRAGE, soluble CD40, and MPO was studied in a randomized, double-blind, clinical trial. ${ }^{51}$ The combination of lercanidipine/enalapril was more effective in reducing $\mathrm{BP}$ compared with the monotherapies as expected. In the same study, ACE inhibitors and CCBs had also neutral effects on lipid and glucose metabolism, but the combination of lercanidipine/enalapril improved Lp(a) more than the single therapies. All treatments increased sRAGE and decreased soluble CD40 and MPO levels, with a better effect seen with the lercanidipine/enalapril combination compared with single monotherapies. These results were not
$\mathrm{BP}$ independent, suggesting that BP reduction with the combination of lercanidipine/enalapril had a more pronounced decreasing effect on endothelial damage that consequently improved LP(a), sRAGE, soluble CD40, and MPO levels.

The metabolic effects of lercanidipine when combined with other antihypertensive drugs have been examined in another study. ${ }^{52}$ Patients with uncomplicated primary hypertension receiving lercanidipine over a period of 24 months but with partial response to treatment additionally received beta blockers, diuretics, ACE inhibitors, and ARBs. The results have shown that independently from the type of drug added, there was an additional BP decrease. A significant decrease in fasting plasma glucose and serum levels of triglycerides has been observed in patients when lercanidipine is combined with an ACE inhibitor or an ARB.

In a retrospective study comparing patients who initially received a combination therapy, the 6-month responder rate was greater for the CCB-based combination (lercanidipine/ enalapril and perindopril/amlopipine) compared to the diuretic-based (enalapril/ramipril/olmesartan and telmisartan with hydrochlorothiazide) groups. ${ }^{53}$

The combination of lercanidipine/enalapril has also been shown to be effective in type II diabetic patients and stage 1 hypertension. Patients with a resting diastolic BP $>90 \mathrm{mmHg}$ were treated with $10 \mathrm{mg}$ enalapril or equipotent doses of other ACE inhibitors (perindopril $4 \mathrm{mg}$ in 6 cases and quinalapril $20 \mathrm{mg}$ in 3 cases) in combination with metoprolol $100 \mathrm{mg}$ for 3 months and subsequently with lercanidipine $10 \mathrm{mg}$ for 3 more months. After 6 weeks on combination treatment, the dose of metoprolol or lercanidipine was uptitrated to $200 \mathrm{mg}$ and $20 \mathrm{mg}$, respectively, when the diastolic BP was still $>90 \mathrm{mmHg}$. After 3 months on lercanidipine, the mean arterial pressure fell by $6 \mathrm{mmHg}$, suggesting that lercanidipine when added to ACE is more effective than metoprolol. Increased cellular expression of glucose transporter type 4 was observed with the lercanidipine/enalapril combination compared to lercanidipine/hydrochlorothiazide. ${ }^{54}$ Activating insulin signaling in human lymphomonocytes may have an important role in patients with diabetes, suggesting that CCB-based drug combinations are more preferable in obese patients or patients with diabetes because of their effects in insulin sensitivity. ${ }^{55}$ Arterial stiffness and augmentation index were studied in hypertensive patients with metabolic syndrome in a study that compared the effect of combination therapy with an ACE inhibitor plus CCB or thiazide diuretic on these parameters. The combination of lercanidipine/ enalapril caused a similar pulse wave velocity reduction as compared to hydrochlorothiazide, but a greater reduction 
in augmentation index indicating a potential additive role on central BP augmentation for the lercanidipine/enalapril combination, which may result in effective protection from target organ damage, such as left ventricular hypertrophy and peripheral vascular damage. ${ }^{56}$ Noninvasive measurements of wall-to-lumen ratio and other morphological parameters of retinal arterioles using scanning laser Doppler flowmetry were evaluated in a study of lercanidipine/enalapril or thiazide diuretic. Patients were treated for 12 months. Capillary density was evaluated by capillaroscopy, and pulse wave velocity and central BP were also measured. Significant improvement of retinal artery structure was observed after treatment with lercanidipine alone, with further improvement with lercanidipine/enalapril, whereas after treatment with lercanidipine/hydrochlorothiazide, the improvement was no longer observed. ${ }^{57}$

A large-scale, randomized, placebo-controlled study on moderate hypertensive patients for the antihypertensive effect of lercanidipine/enalapril was evaluated not only by office but also by home BP changes. The combination of these two drugs was shown to effectively lower BP values both in office and out of office measurements (including 24 hours ambulatory BP and home BP monitoring). ${ }^{58-60}$

\section{Safety and tolerability}

The combination lercanidipine/enalapril was well tolerated in all clinical trials, with similar rates of side effects compared to drugs in monotherapy (Table 3). Generally, cough, dizziness, and vertigo were recorded as adverse events related to the use of the combination lercanidipine/enalapril. ${ }^{48,49}$ Notably, adverse effects specific to the ACE inhibitors such as angioedema and hyperkalemia were not reported. The positive effects of lercanidipine/enalapril combination on lipid and glucose metabolism present an added advantage in the treatment of hypertensive population. ${ }^{19}$ Treatmentemergent adverse effects occurred in only one patient, who

Table 3 Incidence of side effects by monotherapy and lercanidipine/ enalapril combination treatment

\begin{tabular}{|c|c|c|}
\hline Study & Lercanidipine & Lercanidipine + enalapril \\
\hline Puig et al $\left.\right|^{48}$ & Side effects: $12 \%$ & Side effects: $14 \%$ \\
\hline $\begin{array}{l}\text { Maldonado } \\
\text { et al }\left.\right|^{50}\end{array}$ & - & Side effects: $0.3 \%$ \\
\hline \multirow[t]{4}{*}{ Mancia et $\mathrm{a}^{58}$} & L $10 \mathrm{mg}$ side & L 10 mg + E 10 mg side effects: $8.5 \%$ \\
\hline & effects: $6 \%$ & L $10 \mathrm{mg}+\mathrm{E} 20 \mathrm{mg}$ side effects: $10.2 \%$ \\
\hline & L 20 mg side & L 20 mg + E 10 mg side effects: $8.9 \%$ \\
\hline & effects: $8.8 \%$ & L 20 mg + E 20 mg side effects: $8.6 \%$ \\
\hline Scholze et $\mathrm{al}^{60}$ & & L 10 mg + E 20 mg side effects: $3.4 \%$ \\
\hline
\end{tabular}

Abbreviations: L, lercanidipine; E, enalapril. developed a persistent dry cough after the initiation of lercanidipine/enalapril treatment possibly related to enalapril. None of the patients developed edema. Potential adverse events that might be related to the vasodilatory properties of dihydropyridine CCBs may include ankle edema, hot flushes, headache, and palpitations. ${ }^{50}$ The group treated with combination of lercanidipine/enalapril had similar number of palpitation, tachycardia, nervousness, and flushes compared to enalapril/hydrochlorothiazide. ${ }^{49}$ Finally, the tolerability profile of lercanidipine as add-on to enalapril did not differ from previous observations with lercanidipine monotherapy in larger populations. ${ }^{61}$

\section{Patient adherence and satisfaction/ acceptability}

Several studies have compared medication adherence of different drug classes. ${ }^{62,63}$ One study ${ }^{64}$ had focused on the persistence of antihypertensive treatment. Mild-to-moderate hypertensive patients were randomly allocated to monotherapy with either ACE inhibitors, AT-II blockers, CCBs, beta blockers, or diuretics and were followed up for a 24-month period. Persistence of treatment was highest among ACE inhibitors (64.5\%) and AT-II blockers (68.5\%), as compared to $51.6 \%$ of beta blockers (44.8\%) and diuretics (34.4\%). The main reason for drug discontinuation was the occurrence of side effects. ACE inhibitors and ARBs are well known for their favorable side effect profile. CCBs show slightly lower persistence rates. Comparing patients treated with dihydropyridine $\mathrm{CCBs}$, patients were more likely to persist in the lercanidipine treatment compared to other dihydropyridines (59.3\% vs $46.6 \%)$.

Unfortunately, regarding the combination of lercanidipine/enalapril, direct evidence about adherence rates, health care costs, or head-to-head comparisons with other therapeutic regimens does not exist. In an observational study that examined $>8,000$ patients, general practitioners, and specialists in internal medicine, subjective assessment of the lercanidipine/enalapril combination was positive as the efficacy of the fixed combination was assessed by $94 \%$ as "very good" to "good". The physicians also assessed tolerability in $97 \%$ of the patients as "very good" or "good" and assessed adherence as "very good" or "good" in $97 \%$ of patients. ${ }^{65}$ Generally, the once-daily administration of a fixeddose lercanidipine/enalapril $10 \mathrm{mg} / 10 \mathrm{mg}$ or $10 \mathrm{mg} / 20 \mathrm{mg}$ seems to improve BP control in patients not responding to monotherapy and to exert a favorable tolerability profile. Treatment discontinuation due to serious adverse events was reported only in a substantial minority of the patients. 


\section{Conclusion and perspectives}

The purpose of this review was to analyze the efficacy, safety, and tolerability of the combination of lercanidipine with enalapril. The main advantage of combination therapy of lercanidipine/enalapril includes excellent BP control rates with adverse effects comparable to monotherapy. Undoubtedly, patients, especially the elderly, are taking a large amount of pills every day, not only for hypertension but also for other common conditions in the elderly, such as coronary artery disease, type II diabetes, dyslipidemia, depression and sleeping disorders, pain relief, etc. This can result in patients' daily life inconvenience and low adherence rates. Fixed-dose combination drugs may address these issues by reducing the daily number of pills needed, thus improving incorporation into daily life routine and adherence. Furthermore, the choice of fixed-dose combination if associated with a lower incidence of side effects could also increase patient adherence to treatment.

The combination of $\mathrm{ACE}$ and $\mathrm{CCBs}$ show promising results for $\mathrm{CV}$ morbidity and mortality compared to beta blockers and diuretics in clinical trials, but new studies should answer the question of whether these results were drug or class specific. Under this point of view, randomized headto-head clinical trials with other ACE/CCBs combinations assessing hard CV end points are needed. Finally, another important open issue to be addressed is the comparison of ARB- with ACE-based combinations for their effect in hypertension and $\mathrm{CV}$ protection.

\section{Disclosure}

The authors report no conflicts of interest in this work.

\section{References}

1. Page IH. The mosaic theory 32 years later. Hypertension. 1982;4(2):177.

2. Papakatsika S, Stabouli S, Antza C, Kotsis V. Early vascular aging: a new target for hypertension treatment. Curr Pharm Des. 2016;22:122-126.

3. Kotsis V, Grassi G. The enigma of obesity-induced hypertension mechanisms in the youth. J Hypertens. 2016;34(2):191-192.

4. Kotsis V, Nilsson P, Grassi G, et al. New developments in the pathogenesis of obesity-induced hypertension. J Hypertens. 2015;33(8): 1499-1508.

5. Sever P. The heterogeneity of hypertension: why doesn't every patient respond to every antihypertensive drug? J Hum Hypertens. 1995;9(suppl 2):S33-S36.

6. Mimran A, Ribstein J, DuCailar G. Converting enzyme inhibitors and renal function in essential and renovascular hypertension. $\mathrm{Am} \mathrm{J}$ Hypertens. 1991;4(1 pt 2):7S-14S.

7. Dickerson JE, Hingorani AD, Ashby MJ, Palmer CR, Brown MJ. Optimisation of antihypertensive treatment by crossover rotation of four major classes. Lancet. 1999;353(9169):2008-2013.

8. Matterson BJ, Reda DJ, Cushman WC. Department of veterans affairs single-drug therapy of hypertension study. Revised figures and new data. Department of Veterans Affairs Cooperative Study Group on Antihypertensive Agents. Am J Hypertens. 1995;8(2):189-192.
9. Law MR, Wald NJ, Morris JK, Jordan RE. Value of low dose combination treatment with blood pressure lowering drugs: analysis of 354 randomised trials. BMJ. 2003;326(7404):1427.

10. Attwood S, Bird R, Burch K, et al. Within-patient correlation between the antihypertensive effects of atenolol, lisinopril and nifedepin. $J$ Hypertens. 1994;12(9):1053-1060.

11. Chobanian AV, Bakris GL, Black HR, et al. Seventh report of the Joint National Committee on Prevention, Detection, Evaluation, and Treatment of High Blood Pressure. Hypertension. 2003;42(6):1206-1252.

12. Bakris GL, Weir MR, Black HR. Improving blood pressure control rates: is there more we can do? J Clin Hypertens (Greenwich). 2007;9(2):134-142.

13. Jamerson KA, Nwose O, Jean-Louis L, Schofield L, Purkayastha D, Baron M. Initial angiotensin-converting enzyme inhibitor/calcium channel blocker combination therapy achieves superior blood pressure control compared with calcium channel blocker monotherapy in patients with stage 2 hypertension. Am J Hypertens. 2004;17(6):495-501.

14. Taylor AA. Combination drug treatment of hypertension: have we come full circle? Curr Cardiol Rep. 2004;6(6):421-426.

15. Walt DS, Law M, Morris JK, Bestwick JP, Wald NJ. Combination therapy versus monotherapy in reducing blood pressure: meta-analysis on 11,000 participants from 42 trials. Am J Med. 2009;122(3):290-300.

16. Giles T. Rationale for combination therapy as initial treatment for hypertension. J Clin Hypertens (Greenwich). 2003;5(4 suppl 3):4-11.

17. Padilla MC, Armas-Hernández MJ, Hernández RH, Israili ZH, Valasco M. Update on diuretics in the treatment of hypertension. Am J Ther. 2007;14(2):154-160.

18. Weir MR, Crikelair N, Levy D, Rocha R, Kuturu V, Glazer R. Evaluation of the dose response with valsartan and valsartan/hydrochlorothiazide in patients with essential hypertension. J Clin Hypertens (Greenwich). 2007;9(2):103-112.

19. Sowers JR, Neutel JM, Saunders E, et al. Antihypertensive efficacy of Irbesartan/HCTZ in men and women with the metabolic syndrome and type 2 diabetes. J Clin Hypertens (Greenwich). 2006;8(7):470-480

20. Hair PI, Scott LJ, Perry CM. Fixed-dose combination lercanidipine/ enalapril. Drugs. 2007;67(1):95-106.

21. Nash DT. Systolic hypertension. Geriatrics. 2006;61(12):22-28.

22. Dahlof B, Devereux RB, Kjeldsen SE, et al; LIFE Study Group. Cardiovascular morbidity and mortality in the Losartan Intervention For Endpoint reduction in hypertension study (LIFE): a randomised trial against atenolol. Lancet. 2002;359(9311):995-1003.

23. Julius S, Kjeldsen SE, Brunner H, et al; VALUE Trial. VALUE trial: Long-term blood pressure trends in 13,449 patients with hypertension and high cardiovascular risk. Am J Hypertens. 2003;16(7):544-548.

24. Beckett NS, Peters R, Fletcher AE, et al; HYVET Study Group. Treatment of hypertension in patients 80 years of age and older. $N$ Engl $J$ Med. 2008;358:1887-1898.

25. Yusuf S, Sleight P, Pogue J, Bosch J, Davies R, Dagenais G. Effects of an angiotensin-converting-enzyme inhibitor, ramipril, on cardiovascular events in high-risk patients. The Heart Outcomes Prevention Evaluation Study Investigators. $N$ Engl J Med. 2000;342(3):145-153.

26. Liu L, Zhang Y, Liu G, et al; FEVER Study Group. The Felodipine Event Reduction (FEVER) Study: a randomized long-term placebo-controlled trial in Chinese hypertensive patients. J Hypertens. 2005;23:2157-2172.

27. Jamerson K, Weber MA, Bakris GL, et al; ACCOMPLISH Trial Investigators. Benazepril plus amlodipine or hydrochlorothiazide for hypertension in high-risk patients. N Engl J Med. 2008;359(23):2417-2428.

28. Dahlof B, Sever PS, Poulter NR, et al; ASCOT Investigators. Prevention of cardiovascular events with an antihypertensive regimen of amlodipine adding perindopril as required versus atenolol adding bendroflumethiazide as required, in the Anglo-Scandinavian Cardiac Outcomes Trial-Blood Pressure Lowering Arm (ASCOT-BPLA): a multicentre randomised controlled trial. Lancet. 2005;366:895-906.

29. Pepine CJ, Handberg EM, Cooper-DeHoff RM, et al; INVEST Investigators. A calcium antagonist vs. a non-calcium antagonist hypertension treatment strategy for patients with coronary artery disease. The International Verapamil-Trandolapril Study (INVEST): a randomised controlled trial. JAMA. 2003;290(21):2805-2816. 
30. Fox KM; EURopean Trial on Reduction of Cardiac Events with Perindopril in Stable Coronary Artery Disease Investigators. Efficacy of perindopril in reduction of cardiovascular events among patients with stable coronary artery disease: randomised, double-blind, placebo-controlled, multicentre trial (the EUROPA study). Lancet. 2003;362(9386):782-788.

31. Chatzikyrkou C, Haller H, Menne J. Efficacy and safety of fixed-dose Lercanidipine-Enalapril for the treatment of hypertension. Clin Med. 2009; $1: 63-76$

32. Herbette LG, Vecchiarelli M, Sartani A, Leonardi A. Lercanidipine: short plasma half-life, long duration of action and high cholesterol tolerance. Updated molecular models to rationalize its pharmacokinetic properties. Blood Press Suppl. 1998;2:10-17.

33. Otero ML. Manidipine-delapril combination in the management of hypertension. Vasc Health Risk Manag. 2007;3(3):255-263.

34. Bang LM, Chapman TM, Goa KL. Lercanidipine: a review of its efficacy in the management of hypertension. Drugs. 2003;63(22):2449-2472.

35. McClellan KJ, Jarvis B. Lercanidipine: a review of its use in hypertension. Drugs. 2000;60(5):1123-1140.

36. Meredith PA. Lercanidipine: a novel lipophilic dihydropyridine calcium antagonist with long duration of action and high vascular selectivity. Expert Opin Investig Drugs. 1999;8(7):1043-1062.

37. Epstein M. Lercanidipine: a novel dihydropyridine calcium-channel blocker. Heart Dis. 2001;3:398-407.

38. Robles NR, Ocon J, Gomez CF, et al. Lercanidipine in patients with chronic renal failure: the ZAFRA study. Ren Fail. 2005;27(1):73-80.

39. Barrios V, Escobar C, Navarro A, et al; LAURA Study Group. Lercanidipine is an effective and well tolerated antihypertensive drug regardless the cardiovascular risk profile: the LAURA study. Int J Clin Pract. 2006;60(11):1364-1370.

40. Barrios V, Escobar C, de la Figuera M, et al; TOLERANCE study. Tolerability of high doses of lercanidipine versus high doses of other dihydropyridines in daily clinical practice: the TOLERANCE study. Cardiovasc Ther. 2008;26(1):2-9.

41. Poncelet P, Ribstein J, Goullard L, Bassous M, Gres CS, Clerson P. Efficacy and acceptability of lercanidipine are not age dependent in patients with essential hypertension: the AGATE study. Ann Cardiol Angeiol (Paris). 2004;53(3):123-130.

42. Patchett AA. The chemistry of enalapril. Br J Clin Pharmacol. 1984;18(suppl 2):201S-207S.

43. Vlasses PH, Larijani GE, Conner DP, Ferguson RK. Enalapril, a nonsulfhydryl angiotensin-converting enzyme inhibitor. Clin Pharm. 1985;4(1):27-40.

44. Barrios V, Escobar C, Echarri R. Fixed combinations in the management of hypertension: perspectives on lercanidipine - enalapril. Vasc Health Risk Manag. 2008;4(4):847-853.

45. Elung-Jensen T, Heisterberg J, Sonne J, Strandgaard S, Kamper AL. Enalapril dosage in progressive chronic nephropathy: a randomised, controlled trial. Eur J Clin Pharmacol. 2005;61(2):87-96.

46. Messerli FH. Vasodilatory edema: a common side effect of antihypertensive therapy. Curr Cardiol Rep. 2002;4(6):479-482.

47. Gojanovic B, Feihl F, Liaudet L, Waeber B. Concomitant calcium entry blockade and inhibition of the renin-angiotensin system: a rational and effective means for treating hypertension. J Renin Angiotensin Aldosterone Syst. 2008;9(1):1-9.

48. Puig JG, Calvo C, Luurila O, et al. Lercanidipine, enalapril and their combination in the treatment of elderly hypertensive patients: placebocontrolled, randomized, crossover study with four ABPM. J Hum Hypertens. 2007;21(12):917-924.

49. Agrawal R, Marx A, Haller H. Efficacy and safety of lercanidipine versus hydrochlorothiazide as add-on to enalapril in diabetic populations with uncontrolled hypertension. J Hypertens. 2006;24(1):185-192.
50. Maldonado J, Pereira T, Tavares A. Efficacy and safety of a lercanidipine/ enalapril fixed-dose combination in hypertensive patients in Portugal. Drugs R D. 2014;14(2):147-154.

51. Derosa G, Bonaventura A, Romano D, et al. Effects of enalapril/ lercanidipine combination on some emerging biomarkers in cardiovascular risk stratification in hypertensive patients. J Clin Pharm Ther. 2014;39(3):277-285.

52. Cicero A, Gerocarni B, Rosticci M, Borghi C. Blood pressure and metabolic effect of a combination of lercanidipine with different antihypertensive drugs in clinical practice. Clin Exp Hypertens. 2012;34(2):113-117.

53. Angeloni E, Vitaterna A, Lombardo P, Pirelli M, Refice S. Single-pill combination therapy in the initial treatment of marked hypertension: a propensity-matched analysis. Clin Exp Hypertens. 2015;37(5): 404-410.

54. Cleophas TJ, van Ouwerkerk BM, van der Meulen J, Zwinderman AH. Diabetics with hypertension not controlled with ACE inhibitors: alternate therapies. Angiology. 2001;52(7):469-475.

55. Ciuceis C, Flati V, Rossini C, et al. Effect of antihypertensive treatments on insulin signalling in lympho-monocytes of essential hypertensive patients: a pilot study. Blood Press. 2014;23(6):330-338.

56. Ghiadoni L, Bruno R, Cartoni G, et al. Combination therapy with lercanidipine and enalapril reduced central blood pressure augmentation in hypertensive patients with metabolic syndrome. Vascul Pharmacol. 2015.

57. De Ciuceis C, Salvetti M, Rossini C, et al. Effect of antihypertensive treatment on microvascular structure, central blood pressure and oxidative stress in patients with mild essential hypertension. J Hypertens. 2014;32(3):565-574.

58. Mancia G, Coca A, Chazova I, et al; FELT Study Group. Effects on office and home blood pressure of the lercanidipine-enalapril combination in patients with Stage 2 hypertension: a European randomized, controlled clinical trial. J Hypertens. 2014;32(8):1700-1707.

59. Mancia G, Omboni S, Chazovac I, et al; FELT Study Group. Effects on the lercanidipine-enalapril combination vs. the corresponding monotherapies on home blood in hypertension: evidence from a large database. J Hypertens. 2016;34(1):139-148.

60. Scholze J, Bramlage P, Trenkwalder P, Kreutz R. Efficacy and safety of a fixed-dose combination of lercanidipine and enalapril in daily practice. A comparison of office, self-measured and ambulatory blood pressure. Expert Opin Pharmacother. 2011;12(18):2771-2779.

61. Borghi C, Prandin MG, Dormi A, Ambrosioni E; Study Group of the Regional Unit of the Italian Society of Hypertension. Improved tolerability of the dihydropyridine calcium-channel antagonist lercanidipine: the lercanidipine challenge trial. Blood Press Suppl. 2003;1: 14-21.

62. Ambrosioni E, Leonetti G, Pessina AC, Rappelli A, Trimarco B, Zanchetti A. Patterns of hypertension management in Italy: results of a pharmacoepidemiological survey on antihypertensive therapy. Scientific Committee of the Italian Pharmacoepidemiological Survey on Antihypertensive Therapy. J Hypertens. 2000;18(11):1691-1699.

63. Burnier M, Hess B, Greminger P, Waeber B. Determinants of persistence in hypertensive patients treated with Irbesartan: results of a postmarketing survey. BMC Cardiovasc Disord. 2005;5:13.

64. Veronesi M, Cicero AF, Prandin MG, et al. A prospective evaluation of persistence on antihypertensive treatment with different antihypertensive drugs in clinical practice. Vasc Health Risk Manag. 2007;3: 999-1005.

65. Rump LC. Efficacy and tolerability of the fixed lercanidipine-enalapril combination in the treatment of patients with essential hypertension. Arzneimittelforschung. 2010;60(3):124-130. 


\section{Publish your work in this journal}

Vascular Health and Risk Management is an international, peerreviewed journal of therapeutics and risk management, focusing on concise rapid reporting of clinical studies on the processes involved in the maintenance of vascular health; the monitoring, prevention and treatment of vascular disease and its sequelae; and the involvement of metabolic disorders, particularly diabetes. This journal is indexed on PubMed Central and MedLine. The manuscript management system is completely online and includes a very quick and fair peer-review system, which is all easy to use. Visit http://www.dovepress.com/ testimonials.php to read real quotes from published authors.

Submit your manuscript here: https://www.dovepress.com/vascular-health-and-risk-management-journal 